\title{
CLIMATE VARIABILITY AND HUMAN IMPACTS IN CENTRAL AND EASTERN EUROPE DURING THE LAST TWO MILLENNIA
}

\author{
International Conference \\ (Gdańsk, Poland, $1^{\text {th }}-19^{\text {th }}$ June, 2015)
}

The study of regional climatic variability and change is a priority area in current climate and climate-impact research. This is motivated by the facts that: (1) all managed and natural ecosystems including humans are exposed to, and ecosystems services dependent on, local and regional, rather than global manifestations of climate variability and change; (2) amplitudes and rates of climate change are generally much larger on local and regional than on global scales; (3) on these local and regional scales, unforced climate variability may mask or amplify responses of natural forcings, or even be the dominant source of variability on time-scales ranging from the seasonal to the multidecadal. These are all reasons leaving it of fundamental importance that natural forced and unforced variability on regional scales be assessed carefully: natural variability will always be superposed on anthropogenic climate change, and will modify, mask or enhance current and future climate variability, and the impacts of climate change at regional levels.

Proxy-based comprehensive regional climate reconstructions with global (land and ocean) coverage for the past 1000-2000 years (PAGES 2k Working Group; http://www. pages-igbp.org/working groups/2k-network/intro) are cornerstones here, providing an insight into the fundamentals of natural climate variability, and the detection and attribution of anthropogenic climate change in the $20^{\text {th }}$ century. Although significant progress has been made recently, a number of research challenges remain, given that:

- climate reconstructions with complete spatial coverage of land and ocean across all regions of the world are still required;

- new approaches, such as forward modeling of proxy-systems, neural networks etc., are worth exploring; 
- data-model comparisons and data assimilation in model simulations require data expressed in well-defined physical units for a particular calendar season;

- seasonally-resolved climate reconstructions are needed;

- climate reconstructions based on archives such as peat, lake sediments and speleothems are in need of improvement;

- varved lake sediments remain to be much better explored (the PAGES Varves Working Group) and a new PAGES LandCover6k WG has work underway to document land-use changes over the past few millennia.

In line with the above, the CLIMPOL Team and its leaders, Wojciech Tylmann and Prof. Martin Grosjean, aimed to gather paleoclimatologists and paleoecologists from different fields of research to review forced and unforced climate variability and human-environment interactions during the past two millennia and late Holocene. Consequently, the International Conference on 'Climate variability and human impacts in Central and Eastern Europe during the last two millennia' took place on $17^{\text {th }}-19^{\text {th }}$ June 2015 in Gdańsk, Poland. The Conference was organized within the framework of the CLIMPOL project (PSPB-086/2010, www.climpol.ug.edu.pl), as supported by a grant from Switzerland through the Swiss Contribution to the enlarged European Union. The meeting was actively supported by the PAGES International Office and the Association of Polish Geomorphologists. It also represented a contribution to the work of the Varves Working Group, as well as the EuroMed2k and LandCover6k Working Groups.

The event was intended to move forward and stimulate paleoclimate science as regards:

- the filling of regional data gaps in Central Europe and the qualitative improvement of paleoclimate data (calibration, resolution, chronology and interpretation);

- the development of comprehensive multi-site, multi-proxy climate reconstructions with well-understood processes (integrating observational, proxy and model data);

- the understanding and discrimination of multiple influences on ecosystems (climate, human, ecosystem evolution, etc.).

The Conference program included sessions on:

- Historical climatology and documentary data;

- Climate reconstructions from natural archives;

- Past climate modeling, data-model comparisons;

- Proxy calibration, disentangling climate and human impacts;

- Past human impacts on the environment.

Ninety participants from 14 countries attended the Conference hosted by the University of Gdansk. During the three-day meeting, some 43 posters were presented and nearly 40 oral presentations made, among them fifteen keynotes and invited talks serving to introduce the state of the art as regards proxy-based reconstructions and past climate modeling. Contributions dealt with different archives (documentary, lacustrine, peat, tree-ring, cave or borehole), much in high-resolution, and in a well-calibrated and quantitative way. Emphasis was put on the question of how human activities have modified ecosystems in the past, and on how human impact can be distinguished from 
that of climate variability in past ecosystem evolution. Young scientists and experienced researchers had an opportunity to engage in fruitful discussions and to set up new international collaborative ventures. There were meetings of three PAGES Working Groups (Varves WG, LandCover6k and EuroMed2k), and these were open to everyone interested. The scientific content of the Conference was supplemented by a guided city tour and an exhibition of photographs presenting the field work carried out on lakes, as co-organized by the National Information Processing Institute (OPI-IB).

Małgorzata Kinder

Institute of Geography, University of Gdansk 